Jurnal Pendidikan

https://jp.ejournal.unri.ac.id/index.php/JP/index

\title{
MENINGKATKAN HASIL BELAJAR DAN AKTIVITAS SISWA DALAM PEMBELAJARAN IPA MELALUI MODEL PEMBELAJARAN BERBASIS PENEMUAN (DISCOVERY LEARNING) KELAS VI MADINAH SD NEGERI 002 KUOK
}

\author{
Asna \\ SDN 002 Kuok Kabupaten Kampar \\ asna.teacher@outlook.com
}

\begin{abstract}
The purpose of this study was to improve learning outcomes, improve science learning activities for fourth grade students of Madina SD Negeri 002 Terpadu Kuok, Kuok District, Kampar Regency and to motivate teachers to develop learning models and strategies in the science learning process. The research model is Classroom Action Research. This study uses a Discovery Learning model. The application of Classroom Action Research has the objective of improving and or increasing science learning achievement. The results showed: (1) By using the Discovery Learning-based learning model in science learning, student learning outcomes in each cycle experienced significant changes. Student learning outcomes in cycle 1 an average of 71.60 with completeness $22.72 \%$ then increased in cycle 2 an average of 85.93 with completeness $95.45 \%$ with 21 students complete and 1 student who has not completed. Students who are active in learning reach 92\%. After the implementation of the appropriate Discovery Learning-based learning model, the activities and achievements of science learning in Grade VI Madina SD Negeri 002 Integrated Kuok can increase.
\end{abstract}

Keywords: learning outcomes, learning activities, discovery learning

Abstrak:. Tujuan penelitian ini adalah untuk meningkatkan hasil belajar, meningkatkan aktivitas belajar IPA siswa kelas IV Madina SD Negeri 002 Terpadu Kuok Kecamatan Kuok Kabupaten Kampar dan memotivasi guru agar mengembangkan model pembelajaran dan strategi dalam proses pembelajaran IPA. Model penelitian ini adalah Penelitian Tindakan Kelas (PTK). PTK ini menggunakan model Pembelajaran Berbasis Penemuan (Discovery Learning). Penerapan PTK memiliki tujuan untuk memperbaiki dan atau meningkatkan prestasi belajar IPA. Hasil penelitian menunjukkan: (1) Dengan menggunakan model pembelajaran Berbasis Penemuan (Discovery Learning) pada pembelajaran IPA, hasil belajar siswa setiap siklusnya mengalami perubahan secara signifikan. Hasil belajar siswa pada siklus 1 rata-rata 71,60 dengan ketuntasan 22,72 \% lalu meningkat pada siklus 2 rata-rata 85,93 dengan ketuntasan $95,45 \%$ dengan siswa tuntas 21orang dan 1 orang siswa yang belum tuntas. Siswa yang aktif dalam pembelajaran mencapai $92 \%$. Setelah diterapkannya model pembelajaran Berbasis Penemuan (Discovery Learning) yang tepat maka aktivitas dan prestasi belajar IPA pada Siswa Kelas VI Madinah SD Negeri 002 Terpadu Kuok dapat meningkat. 
Kata kunci: hasil belajar, aktivitas belajar, discovery learning

\section{PENDAHULUAN}

Ilmu Pengetahuan Alam adalah ilmu yang mempelajari peristiwa-peristiwa yang terjadi di alam dengan melakukan observasi, eksperimen, penyimpulan, penyusunan teori agar siswa mempunyai pengetahuan,gagasan, dan konsep yang terorganisasi tetang alam sekitar. Pembelajaran IPA di SD/MI bertujuan agar siswa :1) Mengembangkan rasa ingin tahu dan suatu sikap positip terhadap sains teknologi dan masyarakat. 2) Mengembangkan ketrampilan proses untuk menyelidikan alam sekitar, memecahkan masalah dan membuat keputusan.

Namun, pada kenyataan yang terjadi di SD Negeri 002 Kuok guru mendapat kendala dalam meningkatkan hasil belajar siswa pada mata pelajaran IPA, secara khusus pada kompetensi menghubungkan ciri pubertas pada anak laki-laki dan perempuan, kenyataan itu terbukti dari 22 siswa yang mampu tuntas belajar hanya 8 siswa atau 36\%, sedangkan 14 orang siswa nilainya masih rendah atau $63,63 \%$ belum tuntas belajar. Hal itu membuktikan pencapaian hasil belajar IPA masih begitu rendah. Padahal kreteria ketuntasan minimal mata pelajaran IPA yang ditetapkan adalah 78.

Prestasi belajar adalah hasil yang telah dicapai dari yang telah dilakukan / dikerjakan (Kamus Besar Bahasa Indonesia, 2003), sedangkan menurut Tu'u (2004) prestasi belajar adalah penguasaan pengetahuan atau keterampilan yang dikembangkan oleh mata pelajaran, lazimnya ditunjukkan dengan nilai tes atau angka nilai yang diberikan oleh guru.

Prestasi belajar bisa didapatkan melalui adanya proses pembelajaran. Salah satu model yang dapat digunakan dalam proses pembelajaran adalah model pembelajaran discovery learning. Menurut Hosnan (2014), discovery learning adalah suatu model untuk mengembangkan cara belajar aktif dengan menemukan sendiri, menyelidiki sendiri, maka hasil yang diperoleh akan setia dan tahan lama dalam ingatan. Melalui belajar penemuan siswa juga bisa belajar berpikir analisis dan mencoba memecahkan sendiri masalah yang dihadapi. Sedangkan menurut kurniasi, dkk (2014), model Discovery learning adalah proses pembelajaran yang terjadi bila pembelajaran tidak disajikan dengan pelajaran dalam bentuk finalnya, tetapi diharapkan siswa mengorganisasikan sendiri. 
Discovery learning adalah menemukan konsep melalui serangkaian data atau informasi yang diperoleh melalui pengamatan atau percobaan. Kemudian menurut Sund, discovery learning adalah proses mental dimana siswa mampu mengasimilasikan sesuatu konsep atau prinsip. Proses mental tersebut antara lain mengamati, mencerna, mengerti, menggolong-golongkan, membuat dugaan, menjelaskan, mengukur, membuat kesimpulan, dan sebagainya (suryasubrata, 2022).

Pengaplikasian model discovery learning dalam pembelajaran, terdapat beberapa tahapan yang harus dilaksanakan. Kurniasih \& sani (2014) mengemukakan langkah-langkah operasional model discovery learning yaitu sebagai berikut :

a. Langkah persiapan model discovery learning

1) Menentukan tujuan pembelajaran

2) Melakukan identifikasi karakteristik siswa

3) Memilih materi pelajaran

4) Menentukan topik-topik yang harus dipelajari siswa secara induktif

5) Mengembangkan bahan-bahan belajar yang berupa contoh-contoh, ilustrasi, tugas, dan sebagainya untuk dipelajari siswa.

b. Prosedur aplikasi model discovery learning

1) Stimulation (stimulasi)/ pemeberian ransangan)

Pada tahap ini siswa dihadapkan pada sesuatu yang menimbulkan kebingungan, kemudian dilanjutkan untuk tidak memberi generalisasi, agar timbul keinginan untuk menyelidiki sendiri. Guru dapat memulai dengan mengajukan pertanyaan, anjuran membaca buku, dan belajar lainnya yang mengarah pada persiapan pemecahan masalah.

2) Problem statement (pernyataan/ identifikasi masalah)

Guru memberikan kessempatan kepada siswa untuk mengidentikasi masalah-masalah yang relevan dengan bahan pelajaran, kemudian salah satunya dipilih dan dirumuskan dalam bentuk hipotesis.

3) Data collection (pengolahan data) 
Tahap ini siswa diberi kesempatan untuk mengumpulkan berbagai informasi yang relevan, membaca literature, mengamati objek, wawancara, melakukan uji coba sendiri untuk menjawab pertanyaan atau membuktikan benar tidaknya hipotesis.

4) Data processing (pengolahan data)

Pengolahan data merupakan kegiatan mengolah data dan informasi yang telah diperoleh siswa melalui wawancara, observasi dan sebagainya. Tahap ini berfungsi sebagai pembentukan konsep dan generalisasi, sehingga siswa akan mendapatkan pengetahuan baru dari alternatif dan dihubungkan dengan hasil pengolahan data.

5) Verification (pembuktian)

Pada tahap ini siswa melakukan pemeriksaan secara cermat untuk membuktikan benar atau tidaknya hipotesis yang ditetapkan tadi dengan temuan alternative dan dihubungkan dengan dengan hasil pengolahan data.

6) Generalization (menarik kesimpulan/generelasasi)

Tahap generalisasi/ menarik kesimpulan adalah proses menarik sebuah kesimpulan yang dapat dijadikan prinsip umum dan berlaku untuk semua kejadian atau masalah yang sama, dengan memperhatikan hasil verifikasi.

c. Kelebihan model pembelajaran discovery learning adalah:

a) Membantu siswa untuk memperbaiki dan meningkatkan keterampian-keterampilan dan proses-proses kognitif.

b) Pengetahuan yang diperoleh melalui model ini sangat pribadi dan ampuh karena menguatkan pegertian, ingatan, dan transfer.

c) Dapat meningkatkan kemampuan siswa untuk memecahkan masalah.

d) Membantu siswa memperkuat konsep dirinya, karena memperoleh kepercayaan bekerja sama dengan yang lain.

e) Mendorong keterlibatan keaktifan siswa.

f) Mendorong siswa berpikir intuisi dan merumuskan hipotesis sendiri.

g) Melatih siswa belajar mandiri.

h) Siswa aktif dalam kegiatan belajar mengajar, karena ia berpikir dan menggunakan kemampuan untuk menemukan hasil akhir.. 
d. Kelemahan dari model discovery learning yaitu:

a) Menyita banyak waktu karena mengubah cara belajar yang biasa digunakan, namun kekurangan tersebut dapa diminimalisisr dengan merencanakan kegiatan pembelajaran secara terstruktur, memfasilitasi siswa dalam kegiatan penemuan, serta mengonstuksi pengetahuan awal siswa agar pembelajaran dapat berjalan optimal.

b) Tidak efisien untik mengajar jumliah siswa yang banyak, karena membutuhkan waktu yang lama untuk menemukan teori atau pemecahan masalah.

c) Harapan-harapan yang terkandung dalam model ini dapat buyar berhadapan dengan siswa dan guru yang terbiasa dengan cara-cara belajar yang lama.

d) Pengajaran discovery lebih cocok untuk mengembangkan pemahaman, sedangkan mengembangkan konsep,keterampilan dan emosi secara keseluruhan kurang mendapat perhatian.

e) Tidak menyadiakan kesempatan -kesampatan untuk berpikir yang akan ditemukan oleh siswa karena telah dipilih terlebih dahulu oleh guru.

f) Pada beberapa disiplin ilmu ,misalnya IPA kurang fasilitas utuk mengukur gagasan yang dikemukakan oleh para siswa.

\section{METODE PENELITIAN}

Penelitian ini dilaksanakan di kelas VI Madinah SD Negeri 002 Terpadu Kuok, Kecamatan Kuok Kabupaten Kampar dan dilaksanakan selama tiga bulan dari Februari sampai Maret. Subjek penelitian ini adalah siswa kelas VI Madinah Tahun Pelajaran 2018 SD Negeri 002 Kuok Kecamatan Kuok, Kabupaten Kampar. Jumlah peserta didik sebagai subyek penelitian adalah 22 orang yang terdiri dari 14 putra dan 8 putri. Teknik pengumpulan data adalah melalui pengamatan perilaku aktivitas siswa dan tes/ ulangan formatif. Kemudian, teknik pembahasan terbagi menjadi dua, data aktivitas hasil belajar klasikal diharapkan dapat mencapai nilai rerata $70 \%$ sampai dengan $80 \%$ dan data hasil belajar dianalisis berdasarkan ketuntasan belajar yaitu $100 \%$ siswa mencapai hasil $78->78$.

\section{HASIL DAN PEMBAHASAN}

\section{Siklus 1 Pertemuan 1}

Tabel 1. Hasil pengamatan guru dalam observasi 


\begin{tabular}{llcccccc}
\hline \multirow{2}{*}{ No } & \multirow{2}{*}{ Aktifitas Siswa } & Jml Siswa & \multicolumn{5}{c}{ Skor } \\
\cline { 3 - 7 } & & $\mathbf{4}$ & $\mathbf{3}$ & $\mathbf{2}$ & $\mathbf{1}$ \\
\hline 1 & Rasa ingin tahu & 22 & 3 & 6 & 7 & 6 \\
\hline 2 & Cermat & 22 & 4 & 7 & 5 & 6 \\
\hline 3 & Tanggung jawab & 22 & 6 & 3 & 5 & 8 \\
\hline & Jumlah & 66 & 13 & 16 & 17 & 20 \\
\hline & Prosentase \% & $\% 100$ & $19,69 \%$ & $24,24 \%$ & $25,75 \%$ & $30 \%$ \\
\hline
\end{tabular}

Pada lampiran skor keaktifan siswa sebesar 13 dengan persentase 19,69\% dan termasuk kategori amat baik, 16 dengan presentase 24,24\% katagori baik, 17 dengan persentase 25,75\% kategori cukup, dan 20 dengan persentase 30\% kategori kurang. Ditinjau dari keaktifan masingmasing siswa, sebagian besar siswa kurang dalam rasa ingin tahu, cermat, dan tanggung jawab. Sehingga bentuk keaktifan masing-masing individu perlu ditingkatkan dengan menciptakan cara yang lebih mengaktifkan siswa.

1. Pengerjaan soal-soal siklus I. Perilaku siswa terhadap pengerjaan soal-soal siklus I pertemuan 1 ada yang serius, ada yang masih acuh tak acuh,

2. Nilai hasil tes siklus I. Berdasarkan data hasil tes siklus I pada lampiran dapat diketahui nilai rata-rata hasil belajar siswa adalah 68,31 Naik dari nilai sebelum dilakukan pembelajaran model Pembelajaran Berbasis Penemuan (Discovery Learning) yaitu 58,25

Siklus I pertemuan 1 yang diawali dengan perencanaan, tindakkan dan pengamatan berpengaruh pada diri siswa. Pengaruh tersebut dapat dilihat pada kerja sama siswa dalam kelompok dan hasil nilai tes yang dilakukan. Hasil belajar dapat diketahui peningkatannya yaitu pada nilai sebelum dilakukan pembelajaran, rata-rata 58,25 dengan sesudah dilakukan pembelajaran dengan Model Pembelajaran Berbasis Penemuan (Discovery Learning), rata-rata nilai 68,31 masih di bawah KKM yang ditetapkan oleh sekolah sebesar 78 .

\section{Refleksi Siklus 1 Pertemuan 1}

Berdasar hasil pengamatan pada tindakan pertama menunjukkan adanya peningkatan hasil belajar siswa meskipun masih di bawah KKM yang ditetapkan oleh sekolah untuk kelas VI Madinah SD Negeri 002 Kuok sebesar 78. Pada tindakan kedua akan dilakukan bentuk mengaktifkan kerja siswa secara individu, maupun belajar berkelompok. Sehingga ada perubahan yang optimal. Pada pertemuan pertama ada siswa yang kurang aktif dalam pembelajaran. 
Beberapa siswa masih sibuk bermain sendiri, bentuk pembelajaran yang diawali dengan menyanyi secara bersama-sama menumbuhkan minat belajar yang lebih baik.

\section{Siklus 1 Pertemuan 2}

Tabel 2. Hasil pengamatan guru dalam observasi

\begin{tabular}{llccccc}
\hline \multirow{2}{*}{ No } & \multirow{2}{*}{ Aktifitas siswa } & Jml Siswa & \multicolumn{5}{c}{ Skor } \\
\cline { 3 - 7 } & & $\mathbf{4}$ & $\mathbf{3}$ & $\mathbf{2}$ & $\mathbf{1}$ \\
\hline 1 & Rasa ingin tahu & 22 & 8 & 7 & 5 & 2 \\
\hline 2 & Cermat & 22 & 10 & 8 & 2 & 2 \\
\hline 3 & Tanggung jawab & 22 & 9 & 7 & 4 & 2 \\
\hline & Jumlah & 66 & 27 & 22 & 11 & 6 \\
\hline & Persentase \% & $\% 100$ & $49,90 \%$ & $33,33 \%$ & $16,66 \%$ & $9 \%$ \\
\end{tabular}

Pada lampiran skor keaktifan siswa sebesar 27 dengan persentase 49,90\% dan termasuk kategori amat baik, 22 dengan presentase 33,33\% katagori baik, 11 dengan persentase 16,66\% kategori cukup, dan 6 dengan persentase 9\% kategori kurang. Ditinjau dari keaktifan masingmasing siswa, sebagian besar siswa sudah ada peningkatan rasa ingin tahu, cermat dan tanggung jawab. Sehingga bentuk keaktifan masing-masing individu perlu ditingkatkan dengan menciptakan cara yang lebih mengaktifkan siswa.

Siklus 1 Pertemuan 2 yang diawali dengan perencanaan, tindakaan dan pengamatan berpengaruh pada diri siswa. Hasil belajar dapat diketahui peningkatannya yaitu pada nilai setelah dilakukan pembelajaran, rata-rata 74,90 dengan sesudah dilakukan pembelajaran dengan model Discovery Learning, rata-rata dari pertemuan-pertemuan tersebut dapat dituliskan sebagai berikut; 68,31 pertemuan pertama dan 74,90 pada tindakan kedua pertemuan kedua.

\section{Refleksi siklus 1 Pertemuan 2}

Berdasarkan hasil pengamatan pada tindakan kedua menunjukkan adanya peningkatan hasil belajar siswa meskipun masih di bawah KKM yang ditetapkan oleh sekolah untuk kelas VI Madinah SDN 002 Kuok Kecamatan Kuok sebesar 78. Pada tindakan kedua akan dilakukan bentuk mengaktifkan kerja siswa secara individu, maupun berkelompok, sehingga ada perubahan yang optimal. Pada pertemuan pertama ada siswa yang kurang aktif dan kurang interaksi antar siswa. 
Beberapa siswa masih sibuk bermain sendiri. Bentuk pembelajaran yang diawali dengan menyanyi secara bersama-sama menumbuhkan minat belajar yang lebih tinggi.

\section{Siklus 2 Pertemuan 3}

Tabel 3. Hasil pengamatan guru dalam observasi

\begin{tabular}{llccccc}
\hline \multirow{2}{*}{ No } & \multirow{2}{*}{ Aktifitas siswa } & Jml Siswa & \multicolumn{5}{c}{ Skor } \\
\cline { 3 - 7 } & & & $\mathbf{4}$ & $\mathbf{3}$ & $\mathbf{2}$ & $\mathbf{1}$ \\
\hline 1 & Rasa ingin tahu & 22 & 17 & 5 & - & - \\
\hline 2 & Cermat & 22 & 14 & 8 & - & - \\
\hline 3 & Tanggung jawab & 22 & 16 & 6 & - & - \\
\hline & Jumlah & 66 & 47 & 19 & - & - \\
\hline & Prosentase \% & $\% 100$ & $71,21 \%$ & 28,78 & $0 \%$ & $0 \%$
\end{tabular}

Pada lampiran skor keaktifan siswa sebesar 47 dengan persentase $71,21 \%$ dan termasuk kategori amat baik, 19 dengan persentase 28,78\% kategori baik, Ditinjau dari keaktifan masingmasing siswa, sebagian besar siswa sudah amat baik dalam rasa ingin tahu, cermat, dan tanggung jawab. Sehingga bentuk keaktifan masing-masing individu sudah meningkat dengan menciptakan cara belajar yang lebih mengaktifkan siswa.

\section{Refleksi siklus 2 Pertemuan 3}

Berdasarkan hasil pengamatan pada tindakan pertama menunjukkan adanya peningkatan hasil belajar siswa meskipun masih di bawah KKM yang ditetapkan oleh sekolah untuk kelas VI Madinah SDN 002 Kuok Kecamatan Kuok sebesar 78. Pada tindakan ke-4 akan dilakukan bentuk mengaktifkan kerja siswa secara individu sehingga ada perubahan yang optimal.

\section{Siklus 2 Pertemuan 4}

Tabel 4. Hasil pengamatan guru dalam observasi

\begin{tabular}{llll}
\hline No & Aktifitas siswa & Jml Siswa & Skor \\
\hline
\end{tabular}




\begin{tabular}{lllcccc}
\hline & & $\mathbf{4}$ & $\mathbf{3}$ & $\mathbf{2}$ & $\mathbf{1}$ \\
\hline 1 & Rasa ingin tahu & 22 & 19 & 3 & - & - \\
\hline 2 & Cermat & 22 & 21 & 1 & - & \\
\hline 3 & Tanggung jawab & 22 & 21 & 1 & - & - \\
\hline & Jumlah & 66 & 61 & 5 & & \\
\hline & Prosentase \% & $\% 100$ & $92,42 \%$ & $7,57 \%$ & $0 \%$ & $0 \%$ \\
\hline
\end{tabular}

Pada lampiran skor keaktifan siswa sebesar 61 dengan persentase 92,42\% dan termasuk kategori amat baik, 5 dengan persentase $7.57 \%$ dengan katagori baik. Ditinjau dari keaktifan masing-masing siswa, seluruh siswa sudah baik dalam semua aspek.

1. Telah terjadi peningkatan dan menunjukan keaktifan yang sangat maksimal

2. Nilai hasil tes siklus 2 berdasarkan data hasil tes pertemuan ke-4 pada lampiran dapat diketahui nilai rata-rata hasil belajar siswa adalah 88,18 sudah mencapai KKM yang ditetapkan oleh sekolah sebesar 78.

Siklus 2 pertemuan ke-4 yang diawali dengan perencanaan, tindakaan dan pengamatan berpengaruh pada diri siswa. Pengaruh tersebut dapat dilihat pada hasil belajar individu. Hasil belajar dapat diketahui peningkatannya yaitu rata-rata 88,18 dengan sesudah dilakukan pembelajaran dengan model Discovery Learning.

Berdasarkan analisis hasil penilaian dan pengamatan pada siklus 1 dan siklus 2 terjadi adanya peningkatan hal ini dapat terlihat pada rekapitulsi hasil penelitian dibawah ini:

Tabel 5. Rekapitulsi hasil penelitian

\begin{tabular}{lrrrrrr}
\hline SUMBER DATA & NILAI & S1/P1 & S1/P2 & S2/P3 & S2/P4 & KET \\
\hline Aktivitas & 4 & $19,69 \%$ & $40,90 \%$ & $71,21 \%$ & $92,42 \%$ & \\
\cline { 2 - 6 } & 3 & $24.24 \%$ & $33,33 \%$ & $20,70 \%$ & $7,57 \%$ & \\
\cline { 2 - 7 } & 2 & $25,75 \%$ & $16,66 \%$ & $0 \%$ & $0 \%$ & $0 \%$ \\
\hline Hasil Belajar & KKM & $6 \geq$ KKM & $10 \geq$ & $21 \geq$ & $22 \geq$ \\
& & & KKM & KKM & KKM & \\
& & & $90 \%$ & $9 \%$ & &
\end{tabular}




\begin{tabular}{lllll}
\hline Rata- & 68,31 & 74,90 & 83,68 & 88,18 \\
rata & & & \\
Kelas & & & \\
\hline
\end{tabular}

Berdasarkan hasil pengamatan kegiatan kolaborasi dengan teman sejawat dan hasil diskusi dengan peneliti dapat dituliskan sebagai berikut:

1. Kegiatan aktifitas siswa dalam pelaksanaan pembelajaran yang diberikan oleh guru meningkat setelah dilakukan cara pembelajaran dengan variasi model pembelajaran yaitu menggunakan model Discovery Learning dari siklus I 19,69\% menjadi 92,42\% di siklus 2.

2. Pada tes hasil belajar mengalami peningkatan pada siklus 1 masih di bawah KKM yaitu 71.60, tetapi pada tindakan siklus 2 menjadi rata-rata 85,88 di atas KKM yang ditetapkan oleh sekolah sebesar 78 .

Dari uraian di atas dapat disimpulkan sementara bahwa setelah dilakukan beberapa tindakan berupa perencanaan, tindakan pengamatan dan refleksi melalui model Discovery Learning aktifitas belajas siswa, dan tes hasil belajar dapat meningkat.

\section{KESIMPULAN}

Berdasarkan hasil penelitian dan pembahasan dapat disimpulkan bahwa: Pembelajaran dengan menggunakan model Discovery Learning mata pelajaran IPA dapat meningkatkan aktifitas dan prestasi belajar siswa kelas VI Madinah SD Negeri 002 Kuok Kecamatan Kuok yang ditunjukkan pada rata-rata hasil belajar pada siklus 1 sebesar 71,60 menjadi 85,93 pada siklus 2 . Sedangkan presentasi aktivitas siswa pada siklus 1 sebesar 32,29\% dan meningkat menjadi 81,81\% pada siklus 2 .

\section{DAFTAR PUSTAKA}

Arikunto, Suharsimi. (1998). Dasar-dasar Evaluasi Pendidikan. Jakarta : Bumi Aksara

Departemen Pendidikan dan Kebudayaan. (1999). Kamus Besar Bahasa Indonesia. Jakarta: Balai Pustaka

Dimyati \& Mudjiono. (1999). Belajar dan Pembelajaran. Jakarta: Rineka Cipta 
Purwanto, Ngalim. (2007). Psikologi Pendidikan. Bandung: Remaja Rosda Karya Sudjana, Nana. (1995). Penilaian Hasil Proses Belajar Mengajar. Bandung: PT. Remaja Rosda Karya Winkel, W.S. (1996). Psikologi Pengajaran. Jakarta: PT Gramedia Widiasarana Indonesia. 